\title{
Design \& Development of a Variable Height, Removable Watersports Pylon
}

\author{
Fayyaz Rehman ${ }^{\mathrm{a}, 1}$, Charlie $\mathrm{M}^{\mathrm{c}}$ Callum ${ }^{\mathrm{a}}$ \\ a School of Maritime Science \& Engineering, Mechanical Engineering, Southampton \\ Solent University, Southampton SO14 OYN, UK
}

\begin{abstract}
It is the goal of the project to produce a watersports pylon that provides a greater variation in height than has been previously available on the market to meet the needs of both wakeboarders and water-skiers. The secondary goal is to provide a means of operation that does not require permanent fixing to a vessel's deck/structure.

Based on thorough market research, there are options available for invasive pylons that require altering the deck/structure of the vessel, or temporary pylons that can be assembled but do not provide any variation in height. By utilising this gap in the market, it is the desire of the project to produce a product that builds on the existing strengths of similar products without their drawbacks, whilst still being a cost-effective solution.

This project has focused on design of the pylon through all stages of the development process, from market research and product requirements based on customer needs, to design and product development. By developing and understanding the chosen designs using an analytical hierarchy process, the most appropriate option has been determined. The project then developed said design, initially understanding the loads and stresses acting up the pylon, as well as the material requirements. Using these calculations to generate a refined search via appropriate material selection software, the most appropriate material was identified.

The design was then subject to critical structural analysis and optimisation, to ensure the product can be developed to meet the requirements established at the beginning of the project. It was hoped to test a prototype pylon, however the COVID restrictions prevented this.

This paper details the processes of the project and the results produced, which was then critically reviewed to ensure that the pylon meets the initial aims set out at the start of the project.
\end{abstract}

Keywords: Water Sports, Wakeboarding, Water-skiing, pylon, Towing.

\section{Introduction}

Watersports are enjoyed by many people around the world. Other than swimming, these require special equipment to participate. To sail, you need a sailing boat, to row: a rowing boat, to surf: a surfboard. To wakeboard or water ski, you do not just need a boat and board but a means in which you can be pulled along behind said boat. To do this, there are three primary methods, a "wakeboard tower", a "towing harness" or a watersports pylon. The paper is interested in the operation of the watersports pylon.

\footnotetext{
${ }^{1}$ Corresponding Author. fayyaz.rehman@solent.ac.uk
} 
For a pylon to be successful, it needs to be able to achieve the following: It must be of a height greater than or equal to the rider in the water to provide sufficient lift, and to provide a strong, stable platform to be able to safely transfer the forces acting upon it into the deck/structure of the vessel without failure of the pole, mountings, or support. The market currently contains three variations, fixed pylons, removable pylons, and variable height pylons. It is the objective of the project to determine a pylon that combines the strengths of the removable and variable height pylons with the functionality of the fixed pylon.

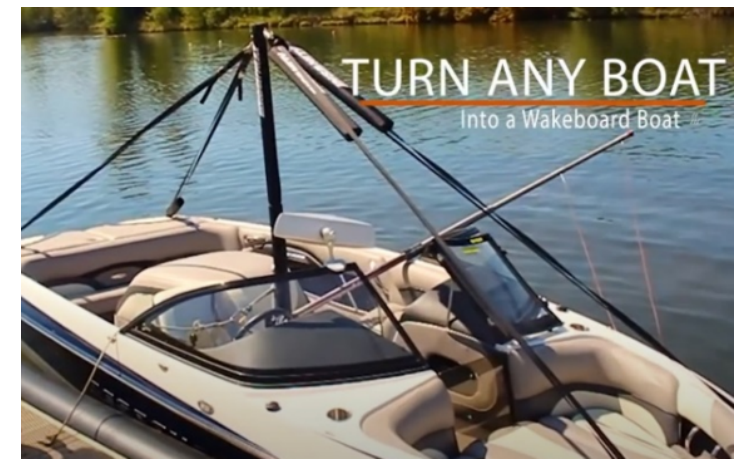

Figure 1: An example of a removable pylon by Insanity wakeboard ${ }^{[1]}$

\section{Design Process}

\subsection{Market study}

To validate a need for a variable and removable watersports pylon, and identify the requirements of said item, a market study was undertaken. This was done via a market analysis which identified imports versus exports, consumer trends, and the popularity of different watersports and their market share, for both the UK and internationally. Additional research was then undertaken to determine the current market climate and what is already available.

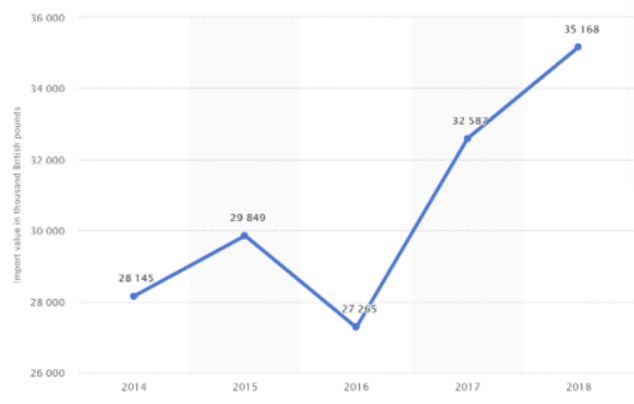

Figure 2: Value of water-skis, surfboards and other water-sport equipment imported to United Kingdom from 2014 to 2018 (in 1,000 British pounds). ${ }^{[3]}$ 


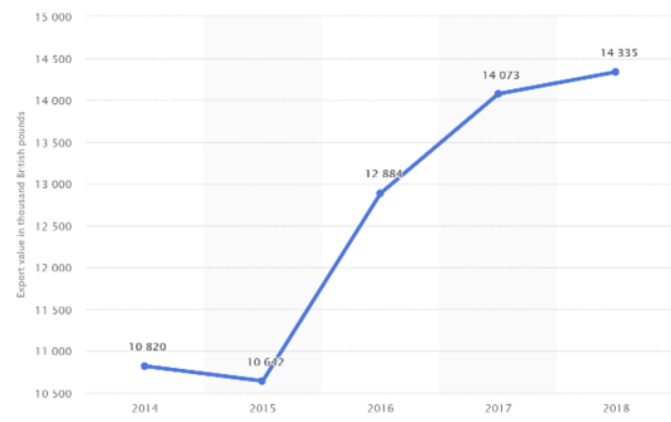

Figure 3: Value of water-skis, surfboards and other water-sport equipment exported from United Kingdom from 2014 to 2018 (in 1,000 British pounds). ${ }^{[2]}$

Now that a potential gap in the market has been identified, suitable investigation is needed into the requirements of the pylon. The primary factors that determine the optimal scenario for participants being towed to perform in are: the speed of the vessel, the way the boat sits in the water, the length of the towing rope and the height of the towing device. The project must consider three of the four options. The first consideration is that of the speed of the boat, as the pylon will have to be able to withstand the force applied on it as it drags the participant up to speed. These speeds are 13 to $22 \mathrm{knots}^{[4]}$. The second consideration is that of the length of the towing rope, as this alters the angle at which said force on the pylon is applied with the length of rope at $19.8 \mathrm{~m}$ to $25.9 \mathrm{~m}$. The final consideration is that of the height of the towing point above the deck of the boat. By providing a higher towing point, a rider can be lifted out of the water easier and have a greater ability for jumps and tricks, with the recommended height being $6-8 \mathrm{ft}^{[5]}$.

During the entire design process, the project needs to be aware and comply with any legislation that may affect it. This includes legislation set out within the merchant shipping regulations and the office of product and safety standards, however the majority legislation is not relevant to the design of watersports pylons, if the design does not affect the critical safety of the vessel. Thankfully, as the project targets vessels $10 \mathrm{~m}$ and under, then merchant shipping regulations concerning vessels of $13.7 \mathrm{~m}$ and above do not apply ${ }^{[6]}$.

\subsection{Development of the design}

A product design specification (PDS) was developed to ensure that the pylon design met the requirements identified above. Initially, multiple designs were generated, with an analytical hierarchy process used to identify the most appropriate. This worked by comparing each design against another based on the needs of the PDS, allowing the design that best met said needs to be identified.

\subsubsection{Identification of forces applied to the pylon.}

In operation, the pylon is subjected to the pull force which is applied when accelerating the participant, and the drag force generated between the equipment being used and the water. As a wakeboard has a greater surface area to that of water-skis, calculations consider the results of a wakeboard in use.

Two scenarios were considered, the first being when the wakeboard is stationary in the water and then pulled up to speed, combined with the lift inducing drag as the board 
is pulled out of the water, and the second scenario is with the wakeboard already in motion and the frictional drag. These two scenarios were compared, with the larger of the two forces (the first scenario) being used within the stress calculations.

Additionally, as the pylon uses stays to hold it into position, the tensional force that these provided to hold it into position and counteract that of the pull force was calculated.

\subsubsection{Stress calculations}

As the pylon acts as a cantilever beam, being fixed at one end and having the opposing forces acting at the other, bending moment calculations were undertaken to understand how the pylon will behave under the applied load. These stresses took into consideration the geometric properties of standard materials available on the market as well.

Using materials that are currently in use in similar marine products on the market, the theoretical and practical section moduli of the design has calculated to ensure that the pylon will not fail. From this, it was determined that stainless steel and Carbon fiber would be appropriate materials, however aluminum would not. Additional calculations were then undertaken on these methods to ensure that the design would not fail by buckling, and to identify the minimum thickness of any welds present.

\subsubsection{Material selection}

Once the design was deemed to be safe and viable, a suitable material selection process was undertaken to determine the best material available for the pylon.

\begin{tabular}{|c|c|c|c|c|}
\hline Function: & Objectives: & Constraints: & Assumptions & Free Variables \\
\hline $\begin{array}{l}\text { - Cheap } \\
\left(C_{m}\right) \text {. } \\
\text { - Light }(\mathrm{m}) \\
\text { - Stiff }(\mathrm{S}) \\
\text { - Strong } \\
\left(\sigma_{\max }\right) \text {. }\end{array}$ & $\begin{array}{l}\text { - Minimise mass. } \\
\text { - Minimise Cost. }\end{array}$ & $\begin{array}{l}\text { - Length is fixed. (L) } \\
\text { - Must not fail under } \\
\text { an applied load. (F) } \\
\text { - Must resist } \\
\text { deformation under } \\
\text { an applied load. } \\
\text { - Must have adequate } \\
\text { toughness. }\left(k_{i c}\right)\end{array}$ & $\begin{array}{l}\text { - It is a hollow pipe } \\
\text { with a uniform } \\
\text { cross section. } \\
\text { - Outer diameter is } \\
1.2 \text { times inner } \\
\text { diameter. } \\
\text { - Fixed at one end } \\
\text { with a point load } \\
\text { at the free end }\end{array}$ & $\begin{array}{l}\text { - Area (A). } \\
\text { - Material. }\end{array}$ \\
\hline
\end{tabular}

Figure 4: Material index requirements

The above table details the material specification that was used to generate relevant material indexes, which were then Inputted into "GRANTA Edu pack" to identify the most appropriate material. These were combined with the requirements that the materials to be considered must have excellent UV and seawater corrosion resistance so that it can survive in the marine environment. The result of this study was that 316 stainless steel was deemed to be the primary material, with the top 6 results being different grades of this material. From these results, the most appropriate material is annealed AISI 316LN Stainless Steel. 


\subsubsection{Generation of a digital model}

To assist in determining how the pylon was going to behave under the forces applied, the initial design that was selected by the AHP was produced on SolidWorks. This provided a visual understanding of the key areas that needed to be examined.

Once the material was identified, a design was produced by combining the geometric properties of standard parts already produced on the market using $316 \mathrm{LN}$ stainless steel to generate a $3 \mathrm{D}$ model that is as close to a working prototype as can be generated on SolidWorks.

\subsubsection{Finite element analysis}

To validate the theoretical calculations against the final design, a finite element analysis (FEA) simulation was produced, using the identified maximum force and material specification imported from GRANTA. The results of this initially had a few areas that did not meet the minimum requirement of a factor of safety (FOS) of three. Therefore, the design had to adjusted to meet the requirement whilst still meeting the needs of the project. Once the design was optimized, the simulation was run again with the optimized design meeting the requirements.

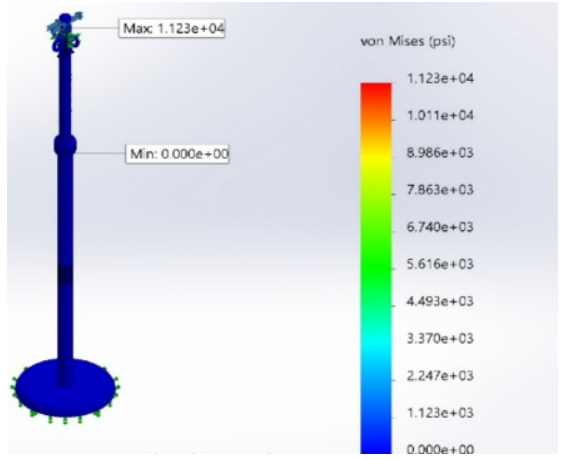

Figure 5: Von Mises stress concentrations

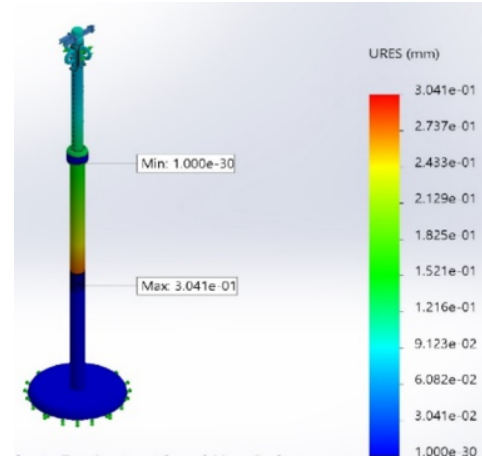

Figure 6: Pylon displacement under load

\section{Final design}

The final design is split into 7 components, which have been designed so that they would be supplied as three should the model be made. From the bottom up, the base of the pylon consists of a standardized tube welded to a base section, with the other end of said tube having a thread cut into it. Next is the middle section which is threaded at one end to join to the base section and contains 2 holes and a locating groove at the other. This is to provide a connection for the locking pin housing. The housing is plastic and is either molded or 3D-printed depending on availability and price. The locking pin shall consist of two stainless steel pins screwed into a plastic body, which has arms to secure it to the housing. The top of the pylon fits inside the middle section and is held in place via the locking pin. It is this part that provides the variable height of the pylon, as it has a series of equally sized and displaced holes along two thirds of the tube length. The top of the tube has holes drilled for three D-rings which are connected to stays which hold it fixed, with two securing to the fore of the boat and one aft. The pylon horn connects to 
the very top of the pylon and provides the point for which the forces generated in towing a participant are transferred into the pylon. This provides a purchase point to allow the tow rope to grip the pylon securely so that it remains attached, whilst still being able to pivot with the needs of the participant.

\section{Prototyping and Testing}

It was the hope of the project to produce a working prototype of the pylon, however due to the restrictions imposed during the COVID pandemic, a working prototype was unable to be produced. It is the hope of the project to be able to produce a pylon when the opportunity arises to validate the findings of the project. A survey was produced to determine the public opinion of the pylon design and functionality; however, the results were limited and although they were favorable, they were not numerous enough to provide any true weight.

\section{Conclusions}

It was the aim of the project to produce a feasible alternative to the current equipment available on the market for towing watersports participants behind a boat, one which is both removable (not of a permanent fixture) and adjustable (height variable). To achieve this, the project was split into specific sections with a clear path on how to progress with each section. In doing so, this allowed the project

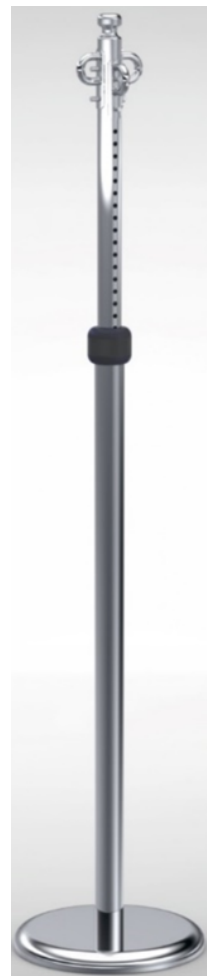

Figure 7: final Design rendering to achieve all the individual requirements of each section to produce a compete and thorough design which meets the objectives set out at the start of the project. This paper has documented the process of product development from idea conception to the final stages of the design, ready to be prototyped and then made available as a working product.

\section{References}

[1]. INSANITY WAKEBOARD AND WATER SKI PYLONS, Insanity Wakeboard and Water Ski Pylons - A No-Drill, Removable Solution [viewed Dec 5, 2020]. Available from: https://insanitypylons.com/

[2]. LANGE, D., 2020a. Export of waterskis and surfboards United Kingdom 2014-18 [viewed Nov 10, 2020]. Available from: https://www.statista.com/statistics/984805/export-waterskis-surfboards-unitedkingdom/

[3]. LANGE, D., 2020b. Imports of waterskis and surfboards United Kingdom 2014-18 [viewed Nov 10, 2020]. Available from: https:/www.statista.com/statistics/984800/imports-waterskis-surfboards-unitedkingdom/

[4]. EVO, 2021. Wakeboarding Tips - Towing Speed, Rope length \& How To Weight Your Boat | evo [viewed Mar 5, 2021]. Available from: https://www.evo.com/guides/wakeboarding-towing-speedrope-length-ballast

[5]. BOATWORLD, 2019. Wakeboard Towers - All Your Questions Answered. In: Blog | Boatworld UK. 11-23T17:00:21+00:00 [viewed Mar 5, 2021]. Available from: https://boatworld.co.uk/blog/wakeboard-tower-guide/

[6]. ROYAL YACHTING ASSOCIATION, 2021. Pleasure craft regulations [viewed March 8, 2021 ]. Available from: https:/www.rya.org.uk/knowledge-advice/regulations/pleasure-craft/Pages/hub.aspx 